\title{
Knowledge and Abilities in Action
}

\author{
JENNIFER HORNSBY, LONDON
}

At the $4^{\text {th }}$ International Wittgenstein Symposium, I presented an account designed to encode what philosophers of action of the 1970s were driving at when they spoke of basic acts (Hornsby 1980). I formulated the account in two different ways-once in terms of belief, again in terms of knowledge. It seemed to me that something important was omitted from a formulation confined to belief, and that it was helpful to convey the relevant idea of what is basic also using the notion of knowledge. Looking back now, I find it unsurprising that I should have wanted to introduce knowledge. I have come to think, quite generally, that accounts of human agency which restrict themselves, on the cognitive side, to belief are inadequate (Hornsby forthcoming).

In the present paper, I want to bring the topic of basic action into relation with a question about the notion of knowing how to. The question is whether someone who is said to know how to do something always has propositional knowledge imputed to them. I think that in order to gain an interesting perspective on this question, we have to get past the standard story of actions as events explained by "belief-desire pairs": we need to pay attention to the role of knowledge and of abilities in rational agency generally. And then, I think, we are led to answer No to the question whether knowledge how to is always propositional.

I start by arguing that people's abilities can be as relevant as their beliefs in explanatory accounts of what they do $(\S 1)$. That takes me to questions about how knowledge and abilities are connected in action, and thus to the idea of knowledge how to $(\S 2)$ and to the particular question about the character of such knowledge $(\S 3)$.

\section{Explanations Of Acting, And Having the Ability To}

Human agents act for reasons. It is understandable that accounts of actionexplanation should be based in the idea of doing something for a reason. According to the standard story, A has a reason to act in a certain way if A has a desire towards something and believes that acting in that way will help secure it. When this conception of a reason for acting is combined with the idea that explanation in terms of reasons is explanation that identi- 
fies causes, one may reach a particular view of the causal antecedents of action (Davidson 1963). Suppose that Ann flipped the switch because she wanted the light on and believed that the switch operated the light. Those who tell the standard story will say that Ann's flipping of the switch was an event of her moving her finger which was caused by her desire and her belief.

Whatever we think of the standard story, if we are interested in any sort of causal story of action, ${ }^{1}$ then we cannot stop with an agent's beliefs and desires. To learn what an agent believed and wanted is not to learn everything that was causally relevant to her action. We appreciate this if we recognize that where ' $\mathrm{X}$ acts because $\mathrm{p}$ ' conveys that $p$ was a reason $\mathrm{X}$ had for acting, then X knew that $p$ (Hyman 1999), (Hornsby forthcoming). And we recognize it again when we see that causal accounts of action can speak of abilities - of what agents are able to do. Let us turn to abilities now.

The fact that Ann was able to flip the light switch was surely relevant to her doing so. She would not have flipped the switch if she had not been able to, and would not have been able to if, for instance, her fingers had been glued together, or she had found herself suddenly paralysed. Of course, in most everyday contexts, an explanation of someone's flipping a switch won't mention their ability to do so. But then in most everyday contexts, any explanation that we actually gave of someone's flipping a switch (should one ever be sought) would hardly need to mention both what the person wanted and what they believed. We leave out the obvious. And, among the most obvious things, which there is ordinarily no need to mention, are what we think of as background conditions. An example from another area would be this. We explain why there was a fire by saying that there was a short-circuit, and we don't mention the presence of oxygen; yet the presence of oxygen - a background condition-was surely relevant causally to the fire's starting. If the fire had started in the absence of oxygen, there would have been a sort of magic. Equally it would be a sort of magic if someone's intentionally doing something were consequential merely on their having a desire and a belief. See further (Gibbons 2001).

But why mention abilities? It might be thought that, from the fact that someone did something, it simply follows that she was able to do it. If so, a

\footnotetext{
${ }^{1}$ Elsewhere I have distinguished the claim that reason-explanations are causal from a central contention of the standard story-that reasons are causes; and I have argued that Davidson's causalist arguments support only the former claim. It is only this claim upon which I rely here. One might say that my concern with causality in what follows is a concern with causal explanation. See e.g. Hornsby 1995.
} 
person's ability could hardly belong in a properly causal account of their doing the thing. But actually to say that someone is able to do something is not to speak merely of the possibility of their doing it. Where ' $a$ can $\Phi$ ' attributes an ability to $a$, it tells us more than that it can be true that $a$ Фs. This is shown in the fact, for instance, that we are reluctant to attribute an ability to do something to someone who does it only by sheer fluke. A person who scores a bullseye with the first dart she ever throws probably lacked the ability to score bullseyes. Arguably there is a sense of 'is able to' according to which, so long as ' $\Phi$ ' is instantiated by a verb of action, one is able to $\Phi$ only if one's $\Phi$-ing can be one's intentionally $\Phi$-ing.

Philosophers who are keen to tell a story of agency in terms of beliefs might say that even though the introduction of abilities seems to bring new explanatory material onto the scene, talk of abilities can actually be reduced to talk of beliefs. They may think that we can record all of the facts about what Ann was able to do which were relevant to her acting as she did by mentioning further beliefs she had. There are three problems about this, however. Looking at these problems will start to show how abilities fit in.

The first problem stems from the fact that beliefs may be false. Ann's belief that she could turn on the light by flipping the switch belongs in an account of Ann's turning on the light only if it is true. Certainly it might be that Ann would have tried to turn on the light even if she had falsely believed that the light switch she flipped was the one she needed to flip. But the light's going on will ensue from Ann's flipping the switch, so that Ann will actually have turned on the light, only if she was right about how to turn it on. If attributing beliefs to agents is to do such work in a causal story as might be done by attributing abilities, then accounts of acting would need to include, for each belief, a matter of particular fact-to the effect that the belief was true. Ann turned on the light because of a desire she had, and because she believed that she could do so by flipping the switch and believed that she could flip the switch by moving her finger and so on, and actually she could turn on the light by flipping that switch and actually she could flip that switch by moving her finger. The explanation we should usually give, which speaks directly to Ann's success and not merely to her attempt, omits these matters of actual fact. And surely the usual explanation, which has no need to mention Ann's various beliefs, can be at least as illuminating.

A second problem about giving beliefs a general role of the sort that abilities might play in action-explanation is familiar. It is what leads to the idea that there must be something basic that the agent does on the occasion 
of any action. A whole series of things may need to be believed to get something done-that one can do THIS by doing THAT, that one can do THAT $b y$ doing THE OTHER, and that one can do THE OTHER $b y$ doing ... , and .. . The links in the 'by'-chain here are more and more basic things the agent does, so that, for instance, if one intentionally does THIS by doing THAT, then THAT is more basic than THIS. (If Ann turned on the light intentionally by flipping the switch intentionally, then flipping the switch is more basic than turning on the light, for instance. ${ }^{2}$ ) But there is a potential regress here, which it must be possible to halt. Unless these 'by'-chains come to an end, an agent will require indefinitely many beliefs about means in order to do anything whatever. Thus there must be some thingsat the end of these 'by'-chains, as it were-which are done without beliefs to the effect that they are done by doing such and such. These are things which we may be inclined to say that agents are simply able to do. They are the teleologically basic things in the terminology of (Hornsby 1980).

Now for the third problem about supposing that beliefs could do the same explanatory work as abilities. Consider once again the simple example of turning on the light. It is natural to think that Ann lacks the ability to do this unless she is able to take the necessary steps to get the light on. Perhaps, before she flips the light switch, Ann has to get up from her seat, walk across the room, and raise her arm so that her finger can be in touch with the switch. And if she is not able to do these things-to take the steps-, then she is not able to turn the light on. These steps are kept out of the picture when the belief-desire theorist treats Ann's turning on the light as a punctuate occurrence, and attributes beliefs in explanation of Ann's turning on the light by saying, for instance 'She believes that she can flip the switch by moving her finger'. But they do belong in an everyday account. For if Ann was in the process of taking the steps needed for her to get the light on and was asked what she was now doing, her answer could perfectly well be 'Turning on the light'.

This last point might be thought to show only that further beliefs need to be brought in. An explanation would have no need to advert to Ann's abilities in the present example if it mentioned (a) her beliefs about what steps she needed to take to turn on the light, and (b) her beliefs about how to carry out each of the needed steps. But however that may be, the exam-

\footnotetext{
${ }^{2}$ When the belief-desire theorists' conception of reasons informs a definition of what is more basic than what, the definition needs to be relativized to occasions of action: see (Hornsby 1980) for some details.
} 
ple draws attention to an unnoticed complexity in the idea of doing one thing by doing another. There are two different sorts of case in which a conjunction of things constitutes an intended means of doing something else-two sorts of case in which an agent whose intended means of Фing are to $\Psi$ and to X. In one sort of case, the agent intentionally ( $\Phi$-s by $\Psi$ ing) and intentionally ( $\Psi$-s by $X$-ing). In the other sort of case, the agent intentionally $\Phi_{\mathrm{s}}$ by ( $\Psi$-ing and $\mathrm{X}$-ing). We have a case of the first sort when Ann's turning on the light is thought of as a simple, punctuate occurrence. Then a single action is taken to have a series of effects (her finger's movement, the switch's flipping, the light's going on). We have a case of the second sort when Ann's turning on the light is thought of as encompassing the various steps which put her in a position to flip the light switch. Then there is no single 'by'-chain corresponding to it. For in respect of each of the components of her turning on the light, which now include the steps she takes, we can ask 'What beliefs of Ann explain her doing that?'. Here we are asking about things that are compositionally more basic.

The simple account of basic action is suited to the sort of examples that recur in action theory (like punctuately turning on a light); and it is not immediately fitted to cases where a compositional notion of basicness has application even before the simple account can be put to work. When we think realistically about actual human agents, cases of the latter sort are rife. It isn't merely that agents' achieving things can sometimes be thought of as encompassing the steps they take to achieve them: many of the things that agents do are obviously composite. Consider making an omelette. We know that one cannot do this without breaking eggs. But there are a whole series of other things that one must also do intentionally-find the eggs and a bowl, whisk, etc. etc.. If we are to have an idea of the basic things someone did when she made an omelette, then we should need to decompose: we should need to isolate the various steps that were taken intentionally, so that we could attend to the 'by'-chains in respect of each. Insofar as a persons's beliefs are explanatory of her $\Phi$-ing, her beliefs in respect of each of the things that she believes make up her $\Phi$-ing must belong in an explanatory account.

Examples could obviously be multiplied. Think of a narrative which tells one in a natural way about what some person did over the course of, say, a few hours. Among the things in the narrative, there will be activities in which the person engaged-travelling to work, conversing with someone, composing a piece of writing, as it might be. Many of the things the person is said to have done (whether or not they are naturally brought un- 
der the head of activities) will be composite, and composite not merely in having sub-components, but in having among the sub-components things in respect of which the agent had beliefs and which she intentionally did.

The beliefs of an agent which we shall now think of as explanatory of acting include beliefs about things in the immediate environment upon which they act and with which they interact-beliefs acquired perceptually, which may be very short-lived. One believes, for instance, that the 'bus is there-at a place which one now moves towards in order to step onto the bus. Here we see an explanatory role for abilities which beliefs alone could never play. The ability someone has, to get home from work, for instance, ensures that they acquire and deploy appropriate beliefs en route. Someone who has this ability is eo ipso able to keep track, and stay in control: without perceptual and cognitive capacities, she couldn't do the various things she needs to do in the course of making her way home.

Human agents participate not only in once-off actions, but also in activities. And they are able so to do.

\section{Knowledge, Abilities and Knowing How to}

When abilities are allowed a place in the explanation of action, it becomes clear how narrowly focused are the explanations from agents' reasons given in the standard story. I said that it would be a sort of magic if someone's intentionally doing something were consequential merely on their having a desire and a belief. And of course we know that reasonexplanations succeed only on the assumption that agents are possessed of various capacities. Some such capacities, such as that which human agents arguably have for self-determining choice, are extremely generic in their scope, and might be exercised on a wide range of occasions. By contrast, the beliefs introduced when an agent's reasons for doing something on a particular occasion are stated may be quite specific. Abilities are explanatory states which operate at an intermediate level of generality as it were. So too, as we shall see now, do some states of knowledge.

We saw that only true beliefs will be mentioned in an account of action if it tells one what the agent actually, successfully did. And it can then seem plausible that when an agent's believing that they can $\Phi$ by $\Psi$-ing is taken to explain their acting, their knowing that they can $\Phi$ by $\Psi$-ing explains it at least as well. At any rate, let us assume that an account of what is basic could be framed in terms of the need to halt a regress not of belief but of knowledge. Thus: whenever someone $\Phi$ s intentionally, there must be 
some thing or things they do for which no piece of knowledge on the pattern of 'I $\Phi$ by - -ing' is needed-some thing or things which they are simply able to do. ${ }^{3}$ We can now raise a question about how explanations from abilities relate to explanations in terms of knowledge.

Start with the simple case. Ann's knowing the location of the relevant light switch had no bearing on whether Ann was able to flip the switch, but it did ensure that she was able to turn on the light that she wanted to. In knowing the whereabouts of the switch, Ann knew of a way to turn it on. Ann's knowledge enabled her intentionally to turn on that light. More generally: knowing a way to do something may enable one to do the thing. Insofar as knowing a way to do something is knowing how to do it, we find here a connection between ability and knowing how to. ${ }^{4}$

Some philosophers say that knowing how to do something is 'in one sense' having the ability to do it: e.g. (Rosefeldt 2004).) Others have wanted quite generally to equate knowing-how-to with having-the-abilityto; e.g. (Noe 2005). But there are counterexamples to such an equation, for instance in (Stanley and Williamson 2001) and (Snowdon 2004). The matter is complicated and controversial, in part because of the enormous context-sensitivity of ascriptions of ability and inability, which makes stable intuitions about cases hard to come by. ${ }^{5}$ Still, it seems very plausible that someone's knowing how to $\Phi$ is not explained by saying that they have the

${ }^{3}$ Relativization to occasions of action (mentioned in the previous footnote) is no longer apt. We are concerned now not with a particular action and the question what beliefs/knowledge were exercised on its occasion, but rather with a question about agents' standing knowledge, which might be exercised on one occasion or another.

${ }^{4}$ In confining attention to knowledge how to, I set to one side the view of (Hyman 1999) according to which knowledge quite generally is a kind of ability. Hyman bases his view on the claim $(\mathrm{H})$ : 'A knows that $p$ if and only if the fact that $p$ can be $a$ 's reason for doing something.' $(\mathrm{H})$ is a fundamental claim about the connection between knowledge and reason, which has application beyond the topic of agency. It seems to me to be true and important. But I have a doubt about the view to which Hyman himself is drawn in consequence of endorsing $(\mathrm{H})$ : see next footnote.

${ }^{5}$ Another factor which can prevent a clear view of cases is that we most readily make judgments about what agents 'are able' to do, rather than about what they 'have the ability' to do, and the judgement that an agent at thas the ability to $\Phi$ seems less demanding than a judgment that the agent at $\mathrm{t}$ is able to $\Phi$. It may be that we need to distinguish between (on the one hand) truths about what an agent 'is able to' do which correspond to their possessing abilities, and (on the other) truths about what an agent 'is able to' do which derive from what is possible. With such a distinction in place, we might be in a position to accept Hyman's important claim (claim $(\mathrm{H})$ of the previous note) without taking Hyman's view that knowledge (generally) just is a kind of ability. 
ability to $\Phi$, but that their having an ability to $\Phi$ might be explained by saying that they know how to. And it is plausible too that an ability to $\Phi$ requires the ability to do all the things needed for one to $\Phi$, whereas knowledge how to $\Phi$ can be possessed in the absence of an ability to do all the things. So we should expect to find counterexamples to the equation. We should expect, for instance, that someone who lacks such bodily capacities as are needed for them to $\Phi$-and who thus lacks the ability to $\Phi$-could nonetheless possess, or retain, their knowledge how to $\Phi$. And indeed many of the examples in the literature are of agents who lose certain abilities needed to do something but who nonetheless retain knowledge of how to do the thing. A different sort of example, which also tells against the equation, is got from the case of a person who knows how to perform fifty press-ups in sequence (she knows how to do one, and then another, and how to count to fifty), but who, for want of sufficient strength and stamina, is always unable to, and lacks the ability to, perform fifty press-ups in sequence. Knowledge how to $\Phi$ does not suffice for the ability to $\Phi$.

One might attempt to use the language of basicness to record a connection that is emerging here between ability to and knowledge how to. Knowledge of how to do things explains one's having such abilities as it may equip one with. And knowledge of how to do something may equip one with the ability to do something provided that one is able to do the needed more basic things. The basic things, we saw, are things which we are apt to say that the agent is simply able to do. And we noticed that in a realistic account, we should sometimes have to decompose the things that agents do into components to uncover basic things. So the proposal might be that what renders one able to do all the various things that one is able to do are, on the one hand, abilities to do basic things, and, on the other hand, knowledge of how do to other things - on the basis of the basic, as it were. The latter sort of knowledge will then take both the form of 'I can $\Phi$ by $\Psi$-ing', 'I can $\Psi$ by X-ing', .. , and also, in order to allow for the sort of compositional basicness we encountered, the form sometimes of 'I can $\Phi$ by ( $\Psi$-ing and X-ing and ...).

This proposal might seem to be congenial to those theorists who wish to identify actions always with bodily movements. They may want to say that all that we can basically do is move our bodies, and that our states of mind confer on us abilities to do all the other things we do. In fact, however, nothing in the line of thought which leads to the idea of basicness suggests that the basic thing an agent does is always to move their body in some way. And we have only to think about bodily activities to appreciate that 
making simple bodily movements is not always basic. Consider walking. No doubt when someone walks they must lift up one leg one moment, drop it the next, then lift up the other leg and drop it, and so on. But presumably it is not as a result of knowing that they must now lift up their right leg that they lift it up now. Insofar as there are things that an agent is simply able to do, walking itself is surely one of them. (Notice that the things one is simply able to do are not to be equated with the simple things one is able to do. Walking is susceptible of decomposition; but knowing how to walk is not a matter of knowing how walking is composed.) Again, someone may know how to carry out complicated dance routines. They may have had to learn exactly what motions one must make to carry out a particular routine, but be able now to carry it out without having retained any detailed knowledge about which sequence of motions one must make in order to do so. And even if they have retained the detailed knowledge, they may not exercise it as they dance. The question whether their dancing is basic for them is not a question about how much they happen to know about what exactly they do, but a question about what knowledge they exercise as they dance, what knowledge actually relevant to their doing what actually they do.

In other examples, the body and its movements appear to have no place in an account. Consider speaking. Most of us have next to no idea of how we move the various bits of our vocal apparatus when we produce the linguistic sounds we do. We can learn something out about this; but if we do, we acquire new knowledge, not just an ability to say something that we had known all along. The example of speech shows not only that the body (the mouth etc. as it would be in the present case) does not come into what is basic. It shows also that decomposition of what is done doesn't always take one to more basic things. Consider that nearly every speaker of English knows how to produce the sentences 'Dogs run' and 'Cats run'; but that very few English speakers are aware that the sounds they make corresponding to the letter 's' are different in each of these strings. So although we can allow that speakers know how to pronounce each of the two sounds (those which complete the words 'dogs' and 'cats'), the knowledge which they exercise when they speak is not exhausted by their knowing how to make each sound. Those who know how to speak follow the rules of phonology; but very few people can state those rules. Perhaps the ordinary speaker knows only this: how to produce such series of sounds as one needs to produce in order to say the things one wants to say. In that case, producing the actual series of sounds one does will be basic. 
There is, then, a conception of the basic that can be elicited by reference to the lack of a certain sort of knowledge: a point is reached at which knowledge of the form 'I can $\Phi$ by $\Psi$-ing' is not attributable to the agent. The agent is simply able to $\Phi$. But still, basic things would seem to be things that agents do know how to do. ${ }^{6}$

The lack of a certain sort of propositional knowledge in respect of basic things may encourage the conclusion that some knowledge how to is of a special, non-propositional sort. But we are not yet forced to that conclusion. For it might be that there is knowledge how to $\Phi$ which, although it is propositional, is not conveyed with something reportable on the pattern of 'I can $\Phi$ by - -ing". If allowance could be made for, as it were, inarticulable knowledge how to $\Phi$-for knowledge how to which is not expressible with instances of the 'by - -ing' scheme-, then we could accommodate the basic without appealing to non-propositional knowledge. Well, inarticulable knowledge in this sense is something introduced in a recent account of 'knowing how to' - as I shall now explain. I shall argue that although the account appears to make room for the idea of things an agent is simply able to do, it is not ultimately satisfactory.

\section{Knowing How to}

The account is due to Stanley and Williamson. They say that knowing how should be subsumed within a general account of knowledge constructions, which deals also with knowing whether, knowing when, where, what, and so on. Knowing whether, or knowing when, or where, or what, would seem always to be a matter of knowing the answer to a question-a question concerning whether or when, or where, or what. If you know where Bob lives, you know the answer to the question 'Where does Bob live?'; if you know what Lynne ate for dinner, you know the answer to the question 'What did Lynne eat for dinner?' But then again, if you know how the conference is organized, you know the answer to the question 'How is the con-

${ }^{6}$ Some may reject not only the sufficiency of knowledge how to - for the ability to -, but also the necessity. They may claim that the agent does not know how to do some basic things. (They may even hold that the force of the claim that we are simply able [say] to raise our arms is that this raising our arms is something we do not know how to do.) Intuitions vary. But most people will agree that there are plenty of things (even if these don't include the making of simple bodily movements) which we $d o$ know how to do, but for which we lack knowledge of propositions that fit the 'by - ing' scheme. 
ference organized?' The point is that the English word 'how', although it doesn't begin with 'wh', still introduces a question. Thus in all of these examples, there appears to be knowledge which is propositional but which is not ascribed using the construction 'know that'.

The present concern of course is 'know how' followed by an infinitive ('knowing how to ..'.). But again the construction is found with the interrogatives 'whether', 'when', 'where', 'what', etc. You may know where to go to find Bill, or what to give Lucy for her Birthday. In Stanley and Williamson's view, the infinitival constructions can always be assimilated to constructions of the previous sort. When an infinitive follows the interrogative particle, there is an empty pronominal element, written 'PRO', in the subject position of the verb; and it is obligatorily linked to the subject of the whole sentence. So 'A knows how to $\Phi$ ' is written 'a knows how PRO to $\Phi$ ' and may be thought to say (roughly) that A knows how A $\Phi$ s. Granted that knowing how to $\Phi$ is knowing a way to $\Phi$, we reach:

A knows how to $\Phi$ if and only if there is some (contextually relevant) way $w$ such that A knows that $w$ is a way for $\mathrm{A}$ to $\Phi .^{7}$

At this point, we see how the inarticulability of some knowledge how to might be accommodated. According to Stanley and Williamson, ways are properties of token events. And it is possible to make reference to such properties without providing a specification of them: one can exploit the presence of samples. So just as you can tell someone what shade of colour your curtains are by pointing to something of the same shade as them and using a demonstrative, saying 'THAT is their colour', so you could tell someone how A $\Phi$-s, by pointing to a token event which is someone's $\Phi$ ing and saying 'THAT is a way for A to $\Phi$ '. There is no need then to resort to an instance of such a locution as 'The way to $\Phi$ is by $\Psi$-ing' in order to say how someone $\Phi$-s. One can make use of the device of deferred ostension, and say 'That is a way'.

This does not yet account for 'A knows how to $\Phi$ '. If it were enough for A to know how to ride a bicycle (say) that A should know about some way of riding a bicycle employed by B that it's a way to ride a bicycle, then one

${ }^{7}$ In order to keep things relatively simple, I shall let 'contextually relevant' take care of itself. Also I shall ride over two distinctions which Stanley and Williamson make which are essential to a complete account: (a) between cases where knowing how to do something is knowing $a$ way to do it and cases where it is knowing the way to do it, (b) between cases where knowing a way to do it is knowing how it can be done and cases where it is knowing how it should be done. 
could learn how to ride a bicycle oneself simply by looking at someone else doing so. But of course one couldn't. In order to account for 'A knows how to $\Phi$ ', where this attributes the distinctive knowledge possessed by someone who can herself ride a bicycle, Stanley and Williamson introduce an idea of propositions being known under practical modes of presentation. Their claim is that 'There's a conventional connection between constructions that embed instances of the "how to $\Phi$ " schema and practical modes of presentations of ways'. So when A is said to know how to ride a bicycle, the proposition knowledge of which is ascribed to A and which contains a way of riding a bicycle, is ascribed, not under a demonstrative mode of presentation, but under a practical one. Stating the account generally, we reach (KHT):

$\mathrm{X}$ knows how to $\Phi$ if and only if for some (contextually relevant) way $w$ which is a way for $\mathrm{X}$ to $\Phi$, there is a practical mode of presentation $m$, such that $\mathrm{X}$ knows under $m$ that $w$ is a way for her to $\Phi$.

Those who are doubtful about the assumption that 'know how to V' is always a case of 'know + how PRO V' may be suspicious of these practical modes of presentation. Suspicions on this score are voiced in (Rosefeldt 2004) and (Koethe 2002). But my own suspicions are about the ways that come into Stanley and Williamson's account. And my objection takes off even before the practical modes are introduced. In order to reach the objection, we need now to think about these putative ways, the things supposedly denoted with demonstratives.

To start with we need to be clear that the fact that someone $\Phi$ s in some way doesn't suffice to show that she knows how to $\Phi$. We can see this with an example. A portion of Beth's website is security protected, so that a password is needed to get into it. Marina thinks that she knows the password, and accordingly types some eight-letter string at the relevant prompt. Actually, however, Marina was lucky enough to have entered the website during the very brief period when any 8 letter string would have succeeded in getting her in. During that period, Beth was altering her security settings, and had had to switch them off. If you ask Marina how to get into Beth's website, then she will give you a wrong answer: she doesn't know how to do this. But of course Marina thinks she knows how to get into the website. She might say "There's a way I used, and I know that it was a way for me to get in, because I actually did get in that way." Marina's thinking that she knows how to get in is based upon her apparently, temporarily, satisfying the right-hand-side of (KHT). But Marina is wrong, so that she doesn't satisfy the left-hand-side. What the example shows is that in order 
to have knowledge how to do something, it is not enough that you should at some time do the thing by luck or by accident. If you know how to do something, then you are equipped not just with any old way of doing it, but with some reliable way, so that you might do the thing in that way on a variety of occasions and on each occasion as a result of knowing how to do it. The ways that belong in an account of knowing how to, then, are only those ways such that their being known by A to be a way for A to do something can constitute A's knowledge of how to do the thing.

I shall now present two examples which suggest that the device of deferred ostension cannot serve to identify such ways. In each example, there is a pair of cases.

Suppose that Kim exercises her knowledge how to type when she types the word 'Afghanistan', which, let us suppose, she has never typed before. You can point at Kim as she types the word, and say 'That's a way for Kim to type'. Inasmuch as she has never typed the word before, one naturally thinks that you are demonstrating a way of typing that Kim has never before deployed. (Not that it isn't a fine way to type the word 'Afghanistan'; it would serve well in the future.) It might be said that deferred ostension can somehow ensure that your 'that' latches onto a more generic way than one we think about when we focus on the fact that Kim has typed only the particular word on this occasion. Perhaps your 'that' refers to a way for Kim to type that has served her often in the past. But now imagine Jo who has not learnt to type, but who has been told that 'Afghanistan' is a good word to start by practising. Jo has typed 'Afghanistan' a few hundred times, and he does it impeccably using all the right fingers, even though he has not yet learnt where most of the letters on the keyboard are located. There may then be no discriminable difference between Jo's typing and Kim's. That means that if it were allowed that your demonstrative could, by deferred ostension, make reference to the way of typing such that Kim knows how to type in virtue of her typing in that way, then we should have to say that Jo too knows how to type. But he doesn't. He knows only how to type 'Afghanistan', and he has a lot to learn.

The other example is Clare, who is pruning the roses. Clare is an excellent gardener who knows how to do this. As she cuts with the secatuers, you say 'That's a way for Clare to prune roses'. Then as she is examining a bit of a plant in order to determine where next to cut, you say again 'That's a way for Clare to prune roses'. If you pick out token events with each of your successive 'that's, then the events you demonstrate have extraordinarily little in common. Clare's hand is in motion when you first say 'that', as 
she cuts; when you say 'that' a second time, her brow is furrowed as she contemplates the next step. But each of these samples of rose pruning ought to serve equally well in displaying the way that Clare, who knows how to prune roses, knows.

If the demonstratives in these examples are to work as the account of knowing how to requires, then each must denote a way of $\Phi$-ing such that its being known by the relevant agent to be a way to $\Phi$ is a case of the agent's knowing how to $\Phi$. But in the first example, of typing 'Afghanistan', we have two different pieces of knowing how (Kim's knowing how to type, and Jo's knowing how to type 'Afghanistan') and only one such way (the way they both typed). In the second example, we have only one piece of knowing how to (Clare's knowing how to prune roses) but two evidently different ways (a way of moving her hand, a way of determining what to do next). Deferred ostension evidently cannot do the work required of it here. It could only work if wherever a person knew how to do something, some single event of their doing it was a manifestation of their knowing how to. But the things we know how to do aren't like that.

\section{Conclusion: Knowing How To and Philosophy of Action}

In criticizing Stanley and Williamson as I have, I do not take the side of the many philosophers who have followed Gilbert Ryle (1949, Ch.2) and assumed that knowledge how to is a species of knowledge distinct from knowledge that. ${ }^{8}$ They have had an eye on a question that can crop up in philosophy of action without taking any account of questions in semantics. Their assumption is cast in doubt, however, as soon as one notices that a person who knows how to do something may know the answer to the question 'How do you do it?'; she may be able to give an answer to this question in words, and, in so doing, articulate a proposition she knows. If a case is really to be made for some distinctive species of know-how, then it cannot depend simply on the presence of the two constructions 'know how to' and 'know that'. If a case is to be made, it would be the one that we uncover when we think about basic action. The case then is a strong one: there are plenty of examples in which a person has knowledge how to $\Phi$

\footnotetext{
${ }^{8}$ Sometimes it is said, and/or said that Ryle said, that knowledge how is a species distinct from knowledge that. But I take it that any such claim intended by Ryle concerned knowledge how to. Or it may have concerned know-how (where no sentence follows the 'how' of 'know-how': one has know-how in respect of some subject).
} 
but appears not to know how she $\Phi$ s-not to know anything which, if it were said, would be an answer to the question how she $\Phi$-s.

The specifically practical modes of presentation invoked by Stanley and Williamson might have provided a distinctive species of know-how, albeit that this would have been a sub-species of propositional knowledge. But I have argued that Stanley and Williamson's account faces a problem. The problem is that the account requires identities between demonstrable ways of $\Phi$-ing (on the one hand) and such ways of $\Phi$-ing as go hand in hand with knowing how to $\Phi$ (on the other hand); and there are not such identities. The examples that I have used to illustrate this might be thought to show that quantification over ways is non-objectual; and then my objection to Stanley and Williamson will be ontological au fond. But however that may be, one would need a positive account of knowing how in order to sustain any view of how talk of ways is rightly understood. Perhaps ways have no place in an account of such knowledge how to as is not propositional knowledge. ${ }^{9}$ Perhaps 'how' following 'know' does not always introduce ways. Then we might understand the claim that someone is simply able to do something as conveying that (although they do know how to do it) there is nothing which is their way of doing it. But whatever the answers are to the questions in semantics, I doubt that we can answer them without having an eye to the metaphysical questions to which philosophy of action leads.

When ways are denoted by such demonstratives as Stanley and Williamson introduce, ways are properties of token events. The problem then arises because a person's knowledge of how to do things informs more than token actions. The problem might go away if all of human agency could be recounted by speaking of series of token events. But the examples of things people do which lead to the introduction of a compositional notion of basicness make it plain that the abilities with which knowledge how to may provide an agent are not confined to abilities to produce tokenevents. As we saw, much human agency is made possible by people's possession of capacities which ensure that they have standing abilities to engage in one or another activity. It might be claimed that activities, such as typing or pruning roses, simply consist, on occasion, in series of token events. The claim seems implausible. But even if this could be made plausible, no-one would think that activities consisted always of homogeneous

\footnotetext{
${ }^{9}$ For criticisms of Stanley and Williamson, presenting challenges to their views about the syntax and semantics of the relevant sentences, see (Rumfitt 2003).
} 
series of such events. And it is the variety in the ways for someone to act which can display her knowledge of how to participate in some one activity which gives rise to the problem for Stanley and Williamson's account.

It can hardly be an accident that, when Ryle made his case for thinking of knowledge-how-to differently from knowledge-that, he concentrated on activities - activities which included playing an instrument, pruning trees, tying a reef-knot, cooking a meal, swimming. The same sort of considerations that lead to seeing the inadequacies of an account of actions as beliefdesire caused bodily movements (the "standard story") would seem to serve to show that there is knowledge how to which is not propositional.

\section{REFERENCES}

Davidson, D. 1963 “Actions, Reasons and Causes", Journal of Philosophy, 23, 685700. (Essay 1 in his Essays on Actions and Events, Oxford: Oxford University Press, 1980.)

Gibbons, J. 2001 "Knowledge in Action", Philosophy \& Phenomenological Research, $62,579-600$.

Hornsby, J. 1980 “Action and Ability”, in Language Logic and Philosophy (Proceedings of the $4^{\text {th }}$ International Wittgenstein Symposium), Vienna: Hoelder-PichlerTempsky, 387-91.

- 1995 "Agency and Causal Explanation", in J. Heil and A. Mele (eds.), Mental Causation, Oxford: Oxford University Press.

- forthcoming 'Knowledge Belief and Reasons for Acting', in Mental Processes: Inference and Representation, eds. M. Beaney, C. Penco and M. Vignolo. Cambridge Scholars Publishing.

Hyman, J. 1999 “How Knowledge Works”, Philosophical Quarterly, 49, 433-51.

Koethe, J. 2002 "Stanley and Williamson on Knowing How", Journal of Philosophy, 99, 325-8.

Noe, A. 2005 “Against Intellectualism”, Analysis, 65, 278-90.

Rosefeldt, T. 2004 "Is Knowing-How Simply a Case of Knowing-That?", Philosophical Investigations, 27, 370-9.

Rumfitt, I. 2003 “Savoir Faire”, Journal of Philosophy, 100, 158-66.

Ryle, G. 1949 The Concept of Mind, London: Hutchinson.

Snowdon, P. 2004 "Knowing How and Knowing That: A Distinction Reconsidered", Proceedings of the Aristotelian Society, 104, 1-32.

Stanley, J. and Williamson, T. 2001 "Knowing How", Journal of Philosophy, 98, 41144. 